\title{
E-Learning Resources for Vascular Surgeons: A Needs Analysis Study
}

Citation for published version (APA):

Matheiken, S. J., Verstegen, D., Beard, J., \& van der Vleuten, C. (2012). E-Learning Resources for Vascular Surgeons: A Needs Analysis Study. Journal of Surgical Education, 69(4), 477-482. https://doi.org/10.1016/j.jsurg.2011.12.008

Document status and date:

Published: 01/01/2012

DOI:

10.1016/j.jsurg.2011.12.008

Document Version:

Publisher's PDF, also known as Version of record

Document license:

Taverne

Please check the document version of this publication:

- A submitted manuscript is the version of the article upon submission and before peer-review. There can be important differences between the submitted version and the official published version of record.

People interested in the research are advised to contact the author for the final version of the publication, or visit the DOI to the publisher's website.

- The final author version and the galley proof are versions of the publication after peer review.

- The final published version features the final layout of the paper including the volume, issue and page numbers.

Link to publication

\footnotetext{
General rights rights.

- You may freely distribute the URL identifying the publication in the public portal. please follow below link for the End User Agreement:

www.umlib.nl/taverne-license

Take down policy

If you believe that this document breaches copyright please contact us at:

repository@maastrichtuniversity.nl

providing details and we will investigate your claim.
}

Copyright and moral rights for the publications made accessible in the public portal are retained by the authors and/or other copyright owners and it is a condition of accessing publications that users recognise and abide by the legal requirements associated with these

- Users may download and print one copy of any publication from the public portal for the purpose of private study or research.

- You may not further distribute the material or use it for any profit-making activity or commercial gain

If the publication is distributed under the terms of Article $25 \mathrm{fa}$ of the Dutch Copyright Act, indicated by the "Taverne" license above, 


\title{
E-Learning Resources for Vascular Surgeons: A Needs Analysis Study
}

\author{
Seán J. Mâtheiken, MBBS, FRCS, ${ }^{* \dagger}$ Daniëlle Verstegen, $P h D,{ }^{\dagger}$ Jonathan Beard, ChM, MEd, FRCS, ${ }^{\ddagger}$ and \\ Cees van der Vleuten, $P h D^{t \mathcal{B} \| \#}$ \\ *London Deanery, London, United Kingdom; ${ }^{\dagger}$ Department of Educational Development and Research, Faculty \\ of Health, Medicine and Life Sciences, Maastricht University, Maastricht, The Netherlands; ${ }^{\ddagger}$ Department of \\ Surgery, University of Sheffield, Sheffield Teaching Hospitals, Sheffield, United Kingdom; §University of \\ Copenhagen, Copenhagen, Denmark; IKing Saud University, Riyadh, Kingdom of Saudi Arabia; and \\ \#Radboud University, Nijmegen, The Netherlands
}

OBJECTIVES: To obtain the views of vascular surgeons about online resources in their specialty as a guide to future e-learning development.

DESIGN: A focused questionnaire regarding e-learning resources in vascular surgery was circulated online. A combination of structured and open-ended questions addressed users' ranking of various resource types, examples of presently used websites, suggestions for future growth, and the opportunity to become actively involved in e-learning development. The responses were collected over a 4-week period and remained anonymous.

SETTING: The study was conducted online at http:// www.vasculareducation.com as part of an ongoing project on e-learning for vascular surgeons by the Department of Educational Development and Research, Faculty of Health, Medicine and Life Sciences, Maastricht University, Maastricht, The Netherlands.

PARTICIPANTS: The survey population consisted of vascular surgeons and surgical trainees in Europe. The participants were contacted via their membership of the European Society for Vascular Surgery and national academic or administrative vascular surgical organizations. Demographic information was collected about clinical seniority and country of work.

RESULTS: In all, 252 responses were obtained. Respondents favored the development of a variety of online resources in vascular surgery. The strongest demand was for illustrations and videos of surgical techniques, followed by an interactive calendar and peer-reviewed multiple-choice questions. Overall, $46 \%$ of respondents wished to contribute actively toward e-learning

Correspondence: Inquiries to Seán Mâtheiken, MBBS, FRCS, Department of Educational Development of Research, Faculty of Health, Medicine, and Life Sciences, 6229 ER, Maastricht, The Netherlands; fax:+44 207681 2080; e-mail: sean.matheiken@gmail.com development, with consultants being more willing than trainees to do so.

CONCLUSIONS: Members of the vascular surgical community value online resources in their specialty, especially for procedural techniques. Vascular surgeons would like to be actively involved in subsequent development of e-learning resources. (J Surg 69:477-482. (C) 2012 Association of Program Directors in Surgery. Published by Elsevier Inc. All rights reserved.)

KEY WORDS: e-learning, web-based learning, online resources, vascular surgery, surgical education

COMPETENCIES: Medical Knowledge, Professionalism, Practice Based Learning and Improvement

\section{INTRODUCTION}

The provision of e-learning, as well as studies evaluating its outcome, are both increasing exponentially in medical disciplines. ${ }^{1}$ The European Society for Vascular Surgery (ESVS) began the development of a stand-alone educational web site for the specialty in 2008 (http://www.vasculareducation.com). An understanding of the types of web resources valued by the target group is important to guide online development and to maximize user compliance. Accordingly, a needs analysis study was designed and conducted to evaluate the preferences of vascular surgeons and trainees for different methods of e-learning and to obtain feedback toward subsequent growth of the website.

\section{MATERIALS AND METHODS}

\section{Questionnaire Design}

The information to be elicited from respondents was listed through detailed discussions among the investigators. The following items were targeted: 
- What kind of online resources do vascular surgeons want to be provided online? Choices included both academic (multiplechoice questions and technical illustrations) and interactive elements (blogs and forums).

- How do vascular surgeons rank various online learning options in terms of importance?

- Which vascular surgical websites, if any, do respondents currently use?

- To what extent would respondents like to participate in the development of vascular surgical e-learning?

Published guidelines for best practice in the design and use of questionnaires were followed. ${ }^{2}$ The following principles were applied:

- Short, unambiguous questions were framed which targeted the data required. Most questions were of the closed answer format; for these, clear answer choices were provided which correlated well with the questions.

- Open-ended questions were provided for respondents to offer feedback and suggestions for future development.

- Relevant demographic data were sought, relating to clinical seniority and primary country of work. Seniority was classified into four groups based on the number of years of experience in vascular surgery; these categories are described in detail in the results. A user-friendly online survey tool (Survey Monkey ${ }^{\mathrm{TM}}$ ) was populated with the selected questions.

The complete questionnaire can be reviewed and attempted online at http://www.vasculareducation.com/needsanalysis_ 2010.

\section{Ethical Approval}

This research was conducted as part of an ongoing project on e-learning for vascular surgeons at the Department of Educational Development and Research, Faculty of Health, Medicine and Life Sciences, Maastricht University. Ethical approval for this study was obtained from the Netherlands Association for Medical Education (NVMO-ERB no. 17 issued on November 15, 2010).

\section{Pilot Study}

The questionnaire was hosted online, and 9 vascular surgeons and trainees were requested to answer the survey. The pilot run concluded with 4 additional feedback questions, as follows:

1. Were the questions easy to understand?

2. Were the answer choices appropriate for the questions?

3. Did we forget to ask for any important information?

4. Do you have any comments or suggestions?

The responses to the pilot study were overwhelmingly positive; all respondents answered "yes" to the first 2 questions. There were 2 "yes" replies to question 3 , which the respondents explained as follows:
(1) “to ask for interest in an 'online meeting place' with or without job opportunities"

(2) "I think it would be good to get an idea of what kind of courses and information vascular surgeons and trainees want. This would help in setting distance courses"

The option "Online forum for discussion" was added to the choice of resources after the suggestions. Having deliberated on the other suggestions offered, we were satisfied that the questionnaire targeted the proposed needs analysis. No other changes were made in the interests of brevity.

\section{Implementation}

The study was hosted online at http://www.vasculareducation.com. The pool of respondents consisted of members of the ESVS, members of the Rouleaux club (the United Kingdom association of trainees in vascular surgery and interventional radiology), and all European trainees in vascular surgery. A short e-mail was drafted to all potential respondents, requesting feedback to guide the subsequent development of online resources for the specialty. Initially, all available European national trainee representatives were contacted, who were requested to pass the message along to their colleagues. ESVS and Rouleaux club members were then e-mailed by the secretaries of those organizations. The study was open to respondents from December 1 to 31, 2010. A reminder e-mail was sent to all Rouleaux Club and ESVS members 7 and 10 days, respectively, after the first invitation.

\section{Analysis}

Survey data were collected using a customized web interface. Results at 50 and 100 responses were compared summarily. The pattern of response remained consistent between these snapshots. It came to light that the ESVS has some nonEuropean members, who could not indicate their country of work using the options provided for demographic data. This was remedied by adding the option "non-European country" during the first week of the study. No other logistical problems were encountered. The study was closed on January 1, 2011, and the responses were tabulated. Data were imported into IBM SPSS Version 19 for Mac (SPSS, Inc, Chicago, Illinois) for statistical analysis.

\section{RESULTS}

Respondents from 43 countries returned 252 questionnaires. Almost a quarter of the responses were from Belgium and Spain; Greece, the United Kingdom, Denmark, and Germany made up another quarter. Eight replies were from non-European countries, 4 of which were from Egypt.

Illustrations of surgical technique scored the highest overall rating and web-conferencing the lowest (Fig. 1). The 4 highest ranked e-learning choices (surgical technique illustrations, sur- 


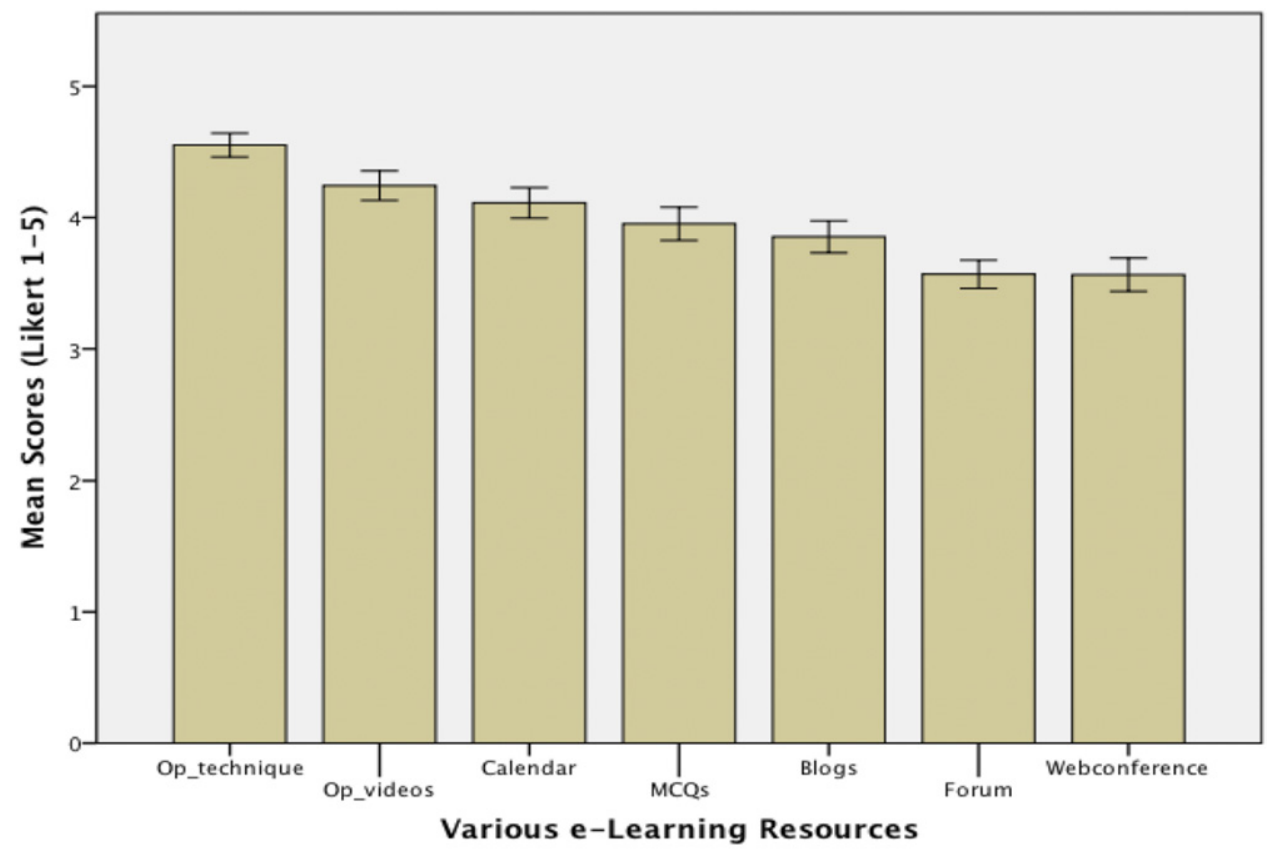

Error Bars: $95 \% \mathrm{Cl}$

FIGURE 1. Ranking of e-L resources in vascular surgery.

gical videos, interactive calendar, and multiple-choice questions) all had a mode of 5/5 on the Likert scale. The measures of central tendency and dispersion for all 7 response items from 252 respondents are provided in Table 1.

Figure 2 illustrates the hierarchy of surgical seniority among respondents. Slightly more than $40 \%$ of responses came from fully qualified vascular surgeons, and almost one fourth came from senior vascular trainees with at least 2 years of specialty experience. Only slightly more than $10 \%$ of responses were from trainees with little or no vascular surgical experience, but nevertheless these individuals were members of named vascular societies, indicating a career preference.

Table 2 illustrates the subtle variations in ratings of e-learning resources across the hierarchy of surgical seniority. In all, 106 respondents were qualified practitioners (consultant vascular surgeons). The remainder consisted of 31 students or trainees with no vascular surgical experience, 53 general surgical or junior vascular surgical trainees, and 62 senior vascular surgical trainees. Students and junior vascular trainees ranked multiple-choice questions (MCQs) above the interactive calendar. Consultants ranked the interactive calendar higher than surgical videos, and blogs were ranked higher than MCQs. Among the resources ranked relatively higher by more junior respondents, an analysis of variance based on seniority revealed the differences to be significant for MCQs ( $F=4.49$, d.f. $=3$, $\mathrm{p}<0.005)$, and operative technique illustrations $(\mathrm{F}=2.739$, d.f. $=3, \mathrm{p}<0.05)$. The only item ranked relatively higher by more senior respondents that achieved significance on analysis of variance was discussion forums $(\mathrm{F}=2.68$, d.f. $=3, \mathrm{p}<0.05)$. The top-ranked resource for all 4 levels of seniority was illustrations of operative technique, with an overall mean score of 4.55 , and subgroup means ranging from 4.42 (consultants) to 4.71 (most junior trainees).

TABLE 1. Measures of Central Tendency and Dispersion for 7 Online Resources

\begin{tabular}{lccccccc}
\hline & $\begin{array}{c}\text { Operative } \\
\text { Technique }\end{array}$ & $\begin{array}{c}\text { Operative } \\
\text { Videos }\end{array}$ & Calendar & MCQs & Blogs & Forum & $\begin{array}{r}\text { Web } \\
\text { Conference }\end{array}$ \\
\hline $\mathrm{N}$ & 252 & 252 & 252 & 252 & 252 & 252 & 252 \\
Mean & 4.55 & 4.24 & 4.11 & 3.95 & 3.85 & 3.57 & 3.56 \\
Standard error of mean & 0.046 & 0.057 & 0.059 & 0.064 & 0.062 & 0.055 & 0.064 \\
Median & 5.00 & 4.00 & 4.00 & 4.00 & 4.00 & 4.00 & 4.00 \\
Mode & 5 & 5 & 5 & 5 & 4 & 3 & 3 \\
Standard deviation & 0.732 & 0.906 & 0.938 & 1.017 & 0.981 & 0.874 & 1.022 \\
Variance & 0.535 & 0.822 & 0.880 & 1.034 & 0.962 & 0.764 & 1.044 \\
Skewness & -2.027 & -1.242 & -0.924 & -0.661 & -0.722 & -0.118 & -0.105 \\
Standard error of skewness & 0.153 & 0.153 & 0.153 & 0.153 & 0.153 & 0.153 & 0.153 \\
Kurtosis & 5.090 & 1.453 & 0.399 & -0.303 & 0.118 & -0.321 & -0.922 \\
Standard error of kurtosis & 0.306 & 0.306 & 0.306 & 0.306 & 0.306 & 0.306 & 0.306 \\
\hline
\end{tabular}




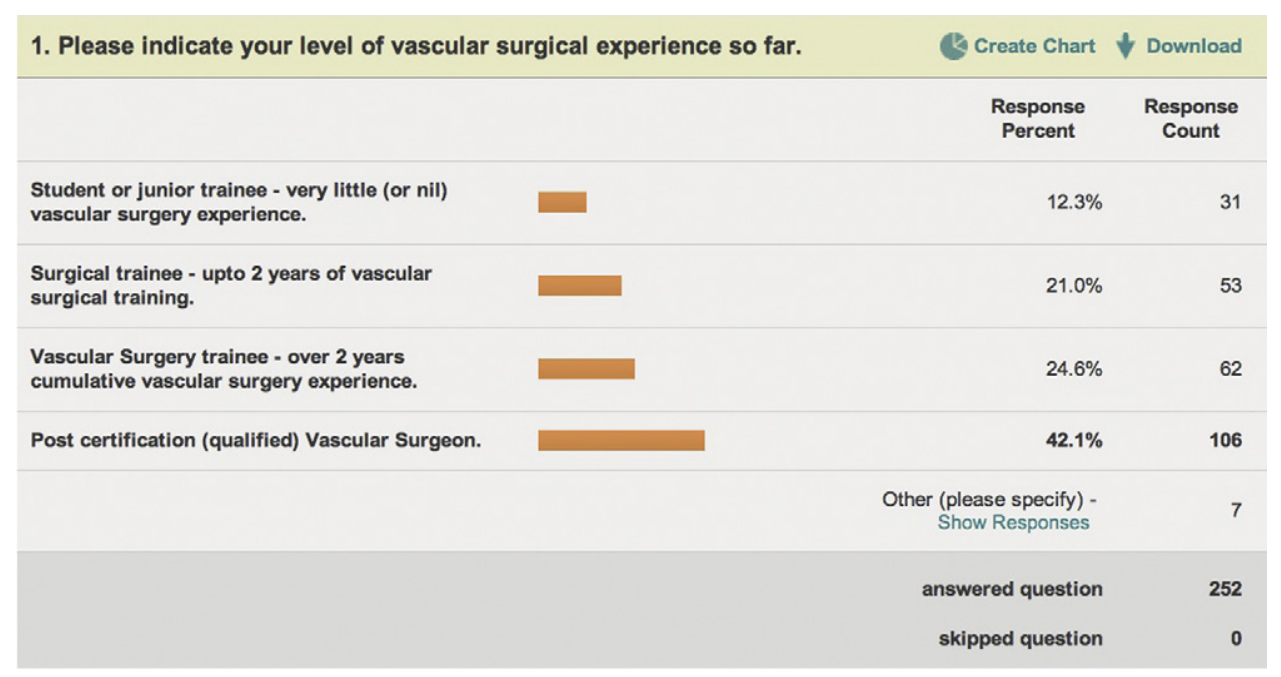

FIGURE 2. Seniority distribution of respondents.

Differences in the attitudes of trainees and consultants toward contributing actively to e-learning development were found. Most of the most junior group (51\%) did not wish to be involved actively in developing resources, whereas most consultants did (58\%). A significant proportion of general surgical (43\%) and vascular surgical (48\%) trainees did not know whether they would like to be involved in e-learning. A mild effect size for positive association between seniority and willingness toward active involvement in e-learning development were found on both Kendall's tau-c $(\tau=0.245, \mathrm{p}<0.005)$ and Spearman's rho $(\rho=0.274, \mathrm{p}<0.005)$ correlations.
In all, 98 percent of surgeons and trainees would like vascular surgical e-learning to be provided free of cost, with accessibility provided to the public (8\%), only medical workers $(33 \%)$, or only members of recognized vascular societies (57\%).

Overall, 55 respondents used the option of free-form text to make comments and suggestions. Relevant content from these is highlighted subsequently.

Many respondents suggested compilation of reviews on the web site, specifically targeting trial updates, guidelines and landmark papers. In the edited words of one enthusiast,

TABLE 2. Ranking of e-Learning Resources Across Hierarchy of Vascular Surgical Seniority

\begin{tabular}{|c|c|c|c|c|c|c|c|}
\hline Vascular Seniority & $\begin{array}{l}\text { Operative } \\
\text { Techniquee }\end{array}$ & $\begin{array}{l}\text { Operative } \\
\text { Videos }\end{array}$ & Calendar & MCQs & Blogs & Forum & $\begin{array}{c}\text { Web } \\
\text { Conference }\end{array}$ \\
\hline \multicolumn{8}{|l|}{$1=$ Junior or student } \\
\hline Mean & 4.71 & 4.48 & 4.19 & 4.45 & 3.94 & 3.52 & 3.48 \\
\hline $\mathrm{N}$ & 31 & 31 & & 31 & 31 & 31 & 31 \\
\hline Standard deviation & 0.643 & 0.811 & 0.873 & 0.995 & 0.772 & 0.851 & 1.061 \\
\hline \multicolumn{8}{|l|}{$2=$ General surgery trainee } \\
\hline Mean & 4.74 & 4.45 & 3.92 & 4.11 & 3.77 & 3.42 & 3.38 \\
\hline $\mathrm{N}$ & 53 & 53 & & & & & 53 \\
\hline Standard deviation & 0.593 & 0.748 & 0.917 & 0.954 & 0.933 & 0.819 & 1.023 \\
\hline \multicolumn{8}{|l|}{$3=$ Vascular trainee } \\
\hline $\begin{array}{l}\text { Mean } \\
N\end{array}$ & 4.53 & 4.11 & 4.05 & 3.90 & 3.84 & 3.42 & 3.47 \\
\hline $\begin{array}{l}\mathrm{N} \\
\text { Standard deviation }\end{array}$ & ${ }^{62} 804$ & 02,960 & 02982 & 62020 & 02,995 & 02 & 62 \\
\hline \multicolumn{8}{|l|}{$4=$ Consultant } \\
\hline Mean & 4.42 & 4.14 & 4.22 & 3.75 & 3.88 & 3.75 & 3.74 \\
\hline $\mathrm{N}$ & 106 & 106 & 106 & 106 & 106 & 106 & 106 \\
\hline Standard deviation & 0.755 & 0.951 & 0.936 & 1.003 & 1.057 & 0.863 & 0.959 \\
\hline \multicolumn{8}{|l|}{ Total } \\
\hline Mean & 4.55 & 4.24 & 4.11 & 3.95 & 3.85 & 3.57 & 3.56 \\
\hline $\mathrm{N}$ & 252 & 252 & 252 & 252 & 252 & 252 & 252 \\
\hline Standard deviation & 0.732 & 0.906 & 0.938 & 1.017 & 0.981 & 0.874 & 1.022 \\
\hline
\end{tabular}

= Medical student or trainee with no vascular surgery experience.

$2=$ General surgery trainee or junior vascular surgery trainee.

3 = Senior vascular surgery trainee (more than 2 years of specialty experience).

$4=$ Qualified vascular surgery consultant. 
This should be a limited list (no more than 10 articles for one type of surgery). It should be kept up to date maybe twice a year ... This would help trainees and surgeons to avoid getting lost in the huge numbers of papers published worldwide."3 Several users commented on the benefit of online expert guidance. This was mooted in the form of discussion threads (similar to the SURGINET forum, an on-demand, ask-the-expert interface about specific topics or a scheduled weekly discussion of complex cases, moderated by experts and accompanied by user votes on what option practitioners would select.

Three surgeons highlighted the use of the online resource to showcase live procedures, with a focus on endovascular cases. Another, from Romania, expressed interest is using the website to gather local endovascular surgeons for mutual benefit.

One user favored the inclusion within http://vasculareducation. com of MCQs from other high impact journals in addition to the European Journal of Vascular and Endovascular Surgery. Another requested online viva questions targeting the Fellowship of the Royal College of Surgeons examination. A professor of vascular surgery opined that, "E-learning should be part of CME and formal accreditation ... E-learning should help trainees to prepare for the ESVS exam, maybe it should be part of the examination." The utility of the website to publicize posts for vascular training or international exchange programs was mentioned in 1 comment.

Some respondents focused on expanding the capabilities of e-learning, such as by developing smartphone and "tablet" device apps. Another novel idea raised was the possibility of allowing users to participate in conferences "virtually," with a subsidized online attendance fee.

Two representative sets of comments are reproduced in toto as follows: One of which suggests a holistic approach to online resource development and the other which summarizes diverse suggestions echoed by a number of other respondents (comments are verbatim except for minor typographical editing):

1. "Some of the major surgical (and other) journals such as the BJS or Lancet use similar ideas or directions on their respective websites. It might be worth (while) to think of pod casts (or podcasts), apps for smart phones, customizable environment of the webpage with the goal to make this page the 'homepage' (with customized access to other resources such as email, web informational resources, weather forecast, timetables for trains/flights etc) etc. to increase traffic/interest on the site and, thus, to 'bind' users to it. This could be the European vascular surgeons' regular platform and homepage for professional life, continued education, resources and possibly even other daily activities." (Respondent on Sunday, December 19, 2010 at 7.19 AM.)

2. "A good idea would be a possibility for every user to select and archive the pages/ content/ articles/ videos/ etc on a personalized area of the website. So that everyone could have a rapid access to what they are interested in. Free and direct access to the main vascular journals for the ESVS members would be nice (EJVES and JVS). Clinical cases/ presentations (once a week?), with survey on which attitude the members would choose. And the answers by recognized experts. International forum, with different categories, for difficult cases, like an international multidisciplinary consultation. A category 'find an expert near you' for expat people, or travelling patients." (Respondent on Sunday, December 19, 2010 1.46 AM.)

Finally, multiple users responded to the inquiry about vascular surgical e-learning resources already in use. The listed websites, in no particular order, included the following: http:// www.endovascular.org, http://www.websurg.com, http:// www.ampsurg.org, http://www.vascularprocedures.com, http://www.esir.org, http://www.rouleauxclub.com, http:// www.esir.org, http://www.medscape.com, and http://www. wikisurgery.com.

\section{DISCUSSION}

This study is a pioneering and comprehensive synthesis of user's views about e-learning resources in vascular surgery. We found that vascular surgeons and trainees overwhelmingly favor the development of online resources for the specialty. The 2 highest ranks were accorded to illustrations and videos of surgical techniques, reflecting the practicality-oriented needs of this population. The provision of an online interactive calendar, equipped with deadlines for abstract submissions and links to scientific meetings, was ranked third. Peer-reviewed, multiplechoice questions ranked fourth of 7 options. The highest variability based on seniority of respondent was observed for this item: Trainees ranked MCQs higher than consultants.

The differences apparent between the responses of trainees and consultants were consistent with their own perceived roles in the specialty. More junior trainees attached greater value to resources that contribute to acquiring academic knowledge (MCQs) and practical know-how (surgical technique illustrations), whereas consultants were more interested than the other groups in interactive facilities, such as the calendar and discussion forum. Conversely, more junior respondents were relatively disinclined to become actively involved in developing e-learning, whereas most consultants expressed a desire to contribute actively towards online resources for the specialty.

An overwhelming majority of participants wished e-learning resources in vascular surgery to be made available free of charge and to restrict access either to members of vascular societies or medical workers. A 2-tier model where some resources require login and password may merit consideration.

The collection of more than 250 responses from specialists in the discipline represents a data sample that is useful to guide future web development. The response rate for a postal survey with no follow up or incentives was $13 \%$ in a previous randomized study of 18 treatment combinations of survey styles. ${ }^{4}$ The corresponding value increased to $25 \%$ after a follow-up letter 2 weeks later. A similar near doubling of response was seen in our study, with 85 responses after the first ESVS e-mail and 72 
responses after the second ESVS e-mail. The low absolute response rate of $12 \%$ may also reflect the short duration over which this study was conducted, its implementation during the festive holiday season, and the online responsiveness of the specific population involved.

This study is subject to self-selection bias. The 252 responses comprise slightly more than $12 \%$ of the membership strength of the ESVS, and $25 \%$ of the responses came from 2 countries, Spain and Belgium, reflecting the active interest taken by national trainee representatives and coordinators in these nations. Similar factors produced improved response rates from the United Kingdom and Greece.

These responses obtained from a community of peers lend impetus to the ongoing development of the ESVS e-learning platform. Multiple-choice questions for learning and an interactive online calendar of vascular events are already available on the e-learning website of the ESVS at the time of this study. Our findings stimulated a formal effort toward procuring suitable vascular surgical e-learning videos, culminating in a successful video competition at the subsequent annual congress of the society. The expressed interest in resources aimed at practical skills led to the initiation of a series of blended learning workshops where online preparatory modules were offered as a prerequisite to the attendance of practical sessions teaching surgical techniques. Almost half of respondents wished to become actively involved in e-learning resource development, with a preponderance of this attitude among more senior trainees and consultants. Many colleagues were recruited accordingly to the e-learning team after their enthusiastic responses to this study, in various capacities as MCQ writers $(\mathrm{n}=8)$, blended learning content editors $(\mathrm{n}=9)$, and vascular surgical illustrator $(\mathrm{n}=$ 1). A significant proportion of vascular surgical trainees said they did not know, yet, whether they would like to participate in e-learning development, representing an opportunity for subsequent web evangelization.

\section{CONCLUSIONS}

Vascular surgical trainees and consultants are in favor of multiple e-learning resources for their specialty. The greatest priority is accorded to illustrations and videos of surgical technique. Surgeons ascribe high value to interactive vascular surgical event calendars and peer-reviewed MCQs. The vascular surgical community wishes such resources to be accessible only to members. There is considerable interest among respondents in actively contributing to the subsequent development of e-learning in vascular surgery.

\section{ACKNOWLEDGMENTS}

The authors greatly appreciate the collaboration and goodwill of the many national trainee coordinators who helped with this study. A special mention is owed to Liesbeth DeSender (Belgium), Fernando Gallardo (Spain), Alan Karthikesalingam (United Kingdom/Rouleaux Club), Thanos Katsargyris (Greece), and Efthimios Avgerinos (Greece).

\section{REFERENCES}

1. Cook DA, Levinson AJ, Garside $S$, et al. Internet-based learning in the health professions: a meta-analysis. JAMA. 2008;300:1181-1196.

2. McColl E, Jacoby A, Thomas L, et al. Design and use of questionnaires: a review of best practice applicable to surveys of health staff and patients. Health Technol Assess. 2001; 5:31.

3. Surginet FAQ page. Available at: http://www3 sympatico.ca/tgilas/SURGINET.FAQ.htm\#anchor15177961.

4. Larson PD, Chow G. Total cost/response rate trade-offs in mail survey research: impact of follow-up mailings and monetary incentives. Ind Mark Manag. 2003;32:533-537. 